In view of the increasing popularity of this technique since the introduction of Marcaine (marketed in 10-ml. ampoules containing bupivacaine $0.5 \%$ + adrenaline $1: 200,000$ ) we feel that these effects should be more widely known and that the use of the undiluted solution should be actively avoided.-We are, etc.

Queen Charlotte's Maternity

Christopher Ruoss.

London W.6.

Jessop Hospital for Women

JOHN M. BEAZLEY.

REFERENCE

1 Page, E. P., Kamm, M. L., and Chappell, C. C., Amer. f.' Obstet. Gynec., 1961, 81, 1094.

\section{Childhood Asthma}

SIR,-Childhood asthma is a common condition. The incidence was $1.76 \%$ of Birming ham schoolchildren. ${ }^{1}$ One-third of all cases of asthma have their onset during the first decade and in one out of four such sufferers the onset dates from the first year. ${ }^{2}$

At this age the diagnosis is entirely clinical. B.B.C.2's programme of 2 May, "Medicine Today," was most confusing. To the concept that asthma is variable airflow obstruction a new factor, ${ }^{34}$ the lability index, is now introduced.

Dr. R. S. Jones (1966) $)^{56}$ is to be congratu lated on this test for latent asthma in hayfever subjects and in the quiescent young adult asthmatic; but this is essentially a respiratory laboratory procedure, and, while furnishing further physiological evidence for the mechanism of asthma, does not benefit the practitioner in the sickroom, particularly as it can be performed only in children over the age of 6 years. Moreover, the complementary article on hyposensitization in childhood asthma (25 May, p. 478) further increases the confusion by reverting to clinical causation. It has been found in the paediatric department of the Prince of Wales Hospital, Tottenham, that skin tests can be of value from the age of 6 months onwards, and if the prick technique is adopted they are not upsetting either to the young or to the nervous child. Moreover, the results have not been affected in any way by the use of steroids. This too has been the experience of Harley.? The article further stresses the removal of allergens in allergic asthma. This is indeed the most important of procedures and should precede any form of desensitizing. In children aqueous solutions or the alum-precipitated extracts are the only solutions to be used. There is no place for the repository method of desensitization in childhood. It is of value only in adults for pollen asthma, but in view of the local and general reactions which may occur it is doubtful whether it should be used at any time. ${ }^{8}-$ We are, etc.,

H. BlaIr.

Prince of Wales Hospital, I. M. ANDERSON. Tottenham, London N.15.

\section{REFERENCES}

I Smith, J. M., Brit. med. F., 1961, 1, 711.

Bray, G. W., Recent Advances in Allergy, 1937 3rd ed. London.

Ciba Guest Symposium, Thorax, 1959, 14, 286

American Thoracic Society, Amer. Rev. resp. Dis. $1963,85,762$.

6 Trefor Jones, R. H., and Jones, R. S., Brit. med. f., 1966, 2, 976 .

Harley, D.. Practitioner, 1960, 184, 421.

- Blair, H., $\ddot{f}$. Coll. gen. Practit., 1968, 15, 317

\section{Osgood-Schlatter's Disease in the Ninth Century?}

SIR,-The abnormal tibia described here was found in the Late Saxon burial ground of St. Catherine, Thorpe, Norwich, and can be dated on archaeological evidence to about the ninth to tenth century A.D. It is now in the Castle Museum, Norwich (Acc. No. $15.953(9)$ ).

It comes from a well-preserved but incomplete body of a middle-aged man. Both tibiae are in perfect condition. The right one is normal, but the left has a defect at the tuberosity. This defect consists of an approximately rectangular trough about 30 $\mathrm{mm}$. long by $20 \mathrm{~mm}$. wide. Its floor is rough and irregular and at its deepest point is about $10 \mathrm{~mm}$. below the normal level of the tuberosity. Distal and medial to this area the bone is somewhat rougher than normal, while the head of the bone anterior to the fibular articulation is exceptionally rough and craggy.

In the inevitable absence of a clinical history it is impossible to be absolutely certain what this lesion is, but several diagnoses suggest themselves. The tibial tuberosity develops from a downward projection of the proximal epiphysis. This may occasionally be detached from the shaft of the bone and develop as a separate ossicle which takes the insertion of the main part of the quadriceps tendon. It is possible that such an anomaly led to the condition found in this specimen, but the appearance of the trough is against this explanation, because under a detached ossicle the bone is usually much smoother and more regular than is found here. Another possibility is that it represents a traction fracture of the tuberosity. In this a flake of bone is torn away from the shaft. Separation may be incomplete, however, and the avulsed flake, which is usually thinner than the depth of this trough would indicate, may remain attached to the rest of the bone by callus. Traction fracture seems an improbable diagnosis in the present case, even though the roughness of the floor of the lesion is campatible with it.

By far the most likely condition here is Osgood-Schlatter's disease. More than 60 years after its first description there is still uncertainty about its cause. In may, as Brailsford $^{1}$ thinks, be due to injury of the chondro-osseous union between tuberosity and shaft from a sudden violent contraction of the quadriceps extensor muscles. Schlatter ${ }^{2}$ thought it was due to apophysitis of the descending process of the epiphysis. On this view it may perhaps be grouped with such osteochondritic lesions as those described by Köhler, Kienböck, Scheuerman, and others. $^{3}$ Whatever the cause of the OsgoodSchlatter lesion, its clinical picture and morbid anatomy are clear enough. Its

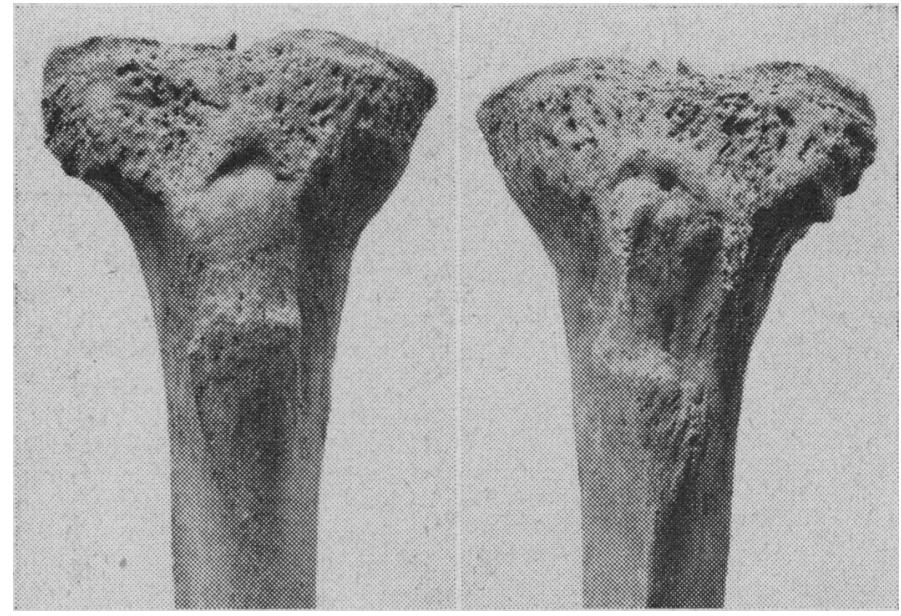

FIg. 1.-Right and left tibiae of Late Saxon date. The left tibia shows probable Osgood-Schlatter's disease.

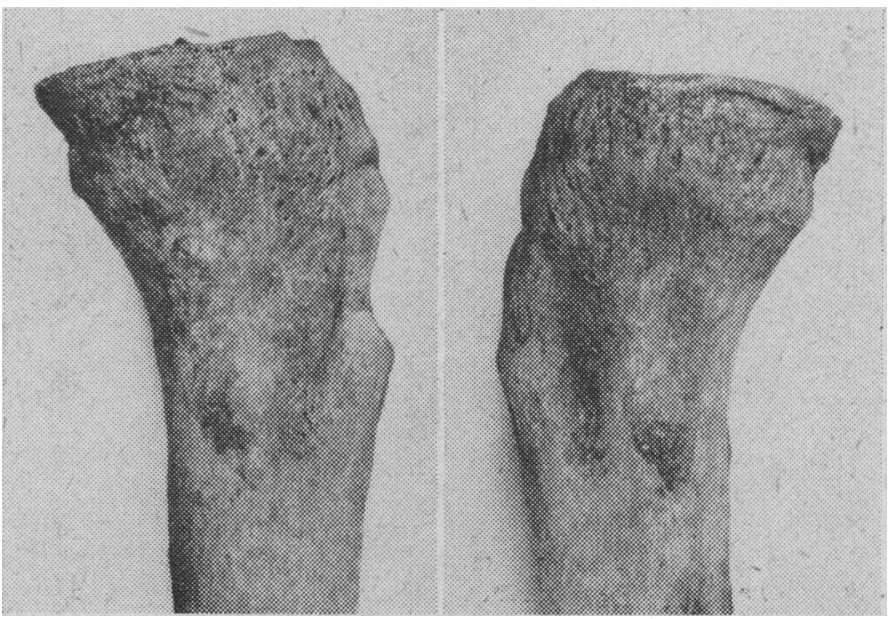

FIG. 2.-The medial view of the same tibiae. (The left tibia is here on the left of the plate.) 
position and appearance are precisely as in the St. Catherine's Thorpe specimen, and it is almost certain that we need look no further for a diagnosis. After the onset of the condition increased stresses are thrown on the medial and lateral extensions of the quadriceps tendon of insertion, with roughening of the bone, as found here. No osteoarthritis, which might suggest a chronic functional disturbance, is present in the hips, knees, or feet of this man, so it seems likely that he suffered little interference with locomotion.

The frequency of Osgood-Schlatter disease in the Saxon period is unknown. In the course of examining about 2,000 tibiae this is the first case I have seen that looks at all convincing.

My thanks are due to Mr. F. W. Cheetham, Director, City of Norwich Museums, for permission to publish this case.

\section{-I am, etc.,}

Norwich,

Norfolk.

Calvin Wells.

\section{REFERENCES}

1 Brailsford, J. F., The Radiology of Bones and foints, 5th ed., 1953. London.

Schlatter, C., Beitr. klin. Chir., 1903, 38, 874. 114.

\section{Ocular Damage due to Paraquat and Diquat}

SIR,-In their article (27 April, p. 224) Mr. J. S. Cant and Dr. D. R. H. Lewis comment that the ocular burn in their case "was similar to that produced by an alkali, which becomes bound to the tissues of the eye, but, unlike alkali burns, the effect was very slow and there was no immediate damage." Lest this should give the impression that eye splashes from the bipyridyls (paraquat and diquat) have all the features of alkali burns, I should like to stress the important differences, not least in prognosis, between bipyridyl and alkali burns, based on experimental study of both types of burn and on following up, with colleagues who have consulted us, the progress of several patients with eye splashes from paraquat or diquat.

The essential difference is in the depth of tissue damage. With alkali, penetration of the eye tissue is extremely rapid, and with all but the smallest splashes deep injury to the cornea is invariably caused, with the attendant danger of permanent interference with vision from subsequent formation of scar tissue. With the bipyridyls the damage, though it may be extensive, is mainly superficial, and, given prompt and adequate treatment to control infection and prevent the formation of adhesions between denuded bulbar and palpebral surfaces, the prospects for full and complete recovery are excellent.

Dr. David Sturman, senior eye registrar at the Wellington Hospital, Wellington, New Zealand, sent us in June 1966 a very full description of the treatment and course of a female patient splashed in both eyes with "Preeglone" Extra. Here the injuries were more severe than in the case of $\mathrm{Mr}$. Cant and Dr. Lewis. The patient was kept in hospital for a total of 23 days, and at first on discharge suffered from some loss of visual acuity in one eye owing to corneal oedema and from epiphora owing to stenosis of both lower puncta and obstruction in the canaliculi. The epiphora was cured by syringing of the lacrimal ducts, and the corneal oedema gradually cleared to give full recovery of vision.

Dr. Sturman's report first alerted us to the fact that the bipyridyls produce more effect in the human eye than our experimental investigations suggested, and it has been the basis of our recommendations in several subsequent cases which have been treated successfully.

It should be added that the labels on all liquid formulations of the bipyridyls carry the warnings: "Wear rubber gloves and face shield when handling the concentrate. Wash concentrate from skin or eyes immediately." -I am, etc.,

$$
\begin{aligned}
& \text { A. A. B. SwAN, } \\
& \text { Director, } \\
& \text { Industrial Hygiene Research Laboratories, } \\
& \text { Imperial Chemical Industries Ltd. }
\end{aligned}
$$$$
\text { Macclesfield, }
$$
Cheshire.

\section{Teratogens and the Abortion Act}

SIR,-In the post-thalidomide era much attention has been directed to the problems of congenital abnormalities produced by external agents of an artificial kind, thus giving impetus to investigations in the field of experimental teratology. With reference to the memorandum from the Medical Defence Union (23 March, p. 759), attention is directed here to the particular circumstance of possible foetal damage as a consequence of some exogenous factor.

Cases of human congenital abnormalities have been reported in association with Asian influenza, carbon-monoxide poisoning, hypoxia, progesterone, insulin, antithyroid substances, maternal diabetes, immunolorical reactions, hyperemesis gravidarum, etc. Few exogenous factors (radiations, rubella, aminonterin, toxoplasmosis, and thalidomide) have been proved, with some degree of certainty, to be teratogenic in man. In these circumstances, where the extrinsic factors are known to be teratogenic in man, termination of pregnancy seems justified.

However, the teratogenicity of a large number of exogenous agents has been demonstrated in various laboratory animals. This suggests possible teratogenicity for humans, and with this a "substantial risk that if the child were born it would suffer from such physical or mental abnormalities as to be seriously handicapped." To what extent can one correlate the results of animal experiments with teratogenicity in the human foetus? The existing animal tests have poor predictive value for human teratogenicitv. Because of the limitations experienced with animal testing and the varying conditions under which these experiments are carried out every effort should be made to standardize methods and define clearly objectives in experimental teratology. Taking these into consideration, animal experiments would continue to provide useful information on the ability of exogenous factors to induce developmental deviations.

Because of the problems involved in allowing an objective assessment from animal experiments, the possibility of a harmfu! effect on the human foetus must be considered when a decision has to be taken with respect to the termination of pregnancy. The systematic collection and analysis of all reports on human teratogenicity, followed by experimen- tal testing of the suspected teratogens in several species of laboratory animals, appear to be useful for the present in guiding such a decision.-I am, etc.,

$$
\text { T. V. N. Persaud. }
$$

Department of Anatomy University of the West Indies,
Jamaica.

\section{Explosion Fractures of Heels}

SIR,-Fractures of the calcaneus arz usually the result of falls, as from scaffolds or ladders. During time of war heel injuries may be sustained by sailors when a torpedo or bomb explosion below decks causes a sudden upward lifting of a ship's plates. A mine exploding under a land vehicle can have the same effect. ${ }^{12}$

Injuries of this kind occurred among a group of civilian workers on a barge in the Hudson River, near Albany, New York, in September 1967. The men were engaged in placing the last of some dynamite charges in $10 \mathrm{~m}$. of water to enlarge a navigation channel. A passing ship failed to slow sufficiently and generated a large wake at the work site.

One of the dynamite loads became fouled in the drilling equipment beneath the barge and exploded, setting off all the other charges. The vessel was lifted 1 or $2 \mathrm{~m}$., throwing the five men on board into the air. Two of the crew fell back on the barge, while the other three were flung into the water. The men were rescued almost immediately, while the barge sank slowly.

Three of the five workers sustained bilateral comminuted fractures of the calcanei. A fourth had fractures of the lower shafts of the tibia and fibula on one side, with a fracture of the neck of the radius on the opposite side, in addition. The fifth man had small fractures of the talus and the navicular bone of one foot and a small compression fracture of the first lumbar vertebra.

One of the victims knowledgeably remarked that it was fortunate that all the charges had gone off together. If an underwater explosion had occurred while any of the men were in the water, they would almost certainly have been killed. ${ }^{3}$ Albany Medical Center Hospital
New York

PAul O'ConNor. REFERENCES

1 Bristow, W. R., 7. Bone 7t Surg. 1943, 25, 524 3 Wakeley, C. P. G., Lancet, 1945, 1, 715 .

\section{Drugs and Hyperthyroidism}

SiR,-In their interesting article (27 April, p. 217) describing the effects of hyperthyroidism on the toxicity of depressant and antidepressant drugs in mice Dr. A. Ashford and Miss Janet W. Ross draw attention to the possible hazards in the use of these drugs in hyperthyroid patients. From the results of our own experiments in rats, in which we have measured the effects of treatment with thyroxine or 3,5,3'-triiodothyronine (2-5 mg./ $\mathrm{kg} . / 9-15$ days s.c.) on sensitivity to a wide range of drugs, we would not only support their warning but also extend it to cover central stimulants and other classes of drugs as well. 